\title{
Quality of smoking cessation advice in guidelines of tobacco-related diseases: An updated systematic review
}

\author{
Authors: Winifred Ekezie, ${ }^{\mathrm{A}}$ Rachael L Murray, ${ }^{\mathrm{B}}$ Sanjay Agrawal, ${ }^{\mathrm{C}}$ Ilze Bogdanovica, ${ }^{\mathrm{D}}$ John Britton ${ }^{\mathrm{E}}$ and \\ Jo Leonardi-Bee ${ }^{F}$
}

Tobacco smoking is a major risk factor for a wide range of diseases, and smoking cessation significantly reduces these risks. Clinical guidelines for diseases associated with smoking should therefore include guidance on smoking cessation. This review updated evidence on the proportion of clinical guidelines that do so. We conducted a systematic review investigating clinical guidelines and recommendations developed by UK national or European transnational medical specialty associations and societies between January 2014 and October 2019 on 16 diseases to be at least twice as common among smokers than non-smokers. Outcomes of interest were the reporting of smoking as a risk factor, and the inclusion either of smoking cessation advice or referral to other cessation guidance. We compared our findings with an earlier review of guidelines published between 2000 and 2013. We identified 159 clinical guidelines/recommendations. Over half $(51 \%)$ made no mention of smoking, while $43 \%$ reported smoking as a risk factor for the development of the disease, $31 \%$ recommended smoking cessation and $19 \%$ provided detailed information on how to deliver smoking cessation support. These proportions were similar to those in our earlier review. Smoking cessation continues to be neglected in clinical management guidance for diseases caused by smoking.

KEYWORDS: Smoking, smoking cessation, guidelines, systematic review

DOI: $10.7861 /$ clinmed.2020-0359

\section{Introduction}

Tobacco smoking is the largest avoidable cause of premature death and disability in the UK, and is more prevalent in the

Authors: ${ }^{\text {A }}$ research associate, University of Nottingham, Nottingham, UK; ${ }^{\text {B }}$ professor of population health, University of Nottingham, Nottingham, UK; ${ }^{C}$ consultant in respiratory and intensive care medicine, Glenfield Hospital, Leicester, UK; ${ }^{\text {D principal }}$ research fellow, University of Nottingham, Nottingham, UK; Eprofessor of epidemiology, University of Nottingham, Nottingham, UK; ${ }^{F}$ professor of medical statistics and epidemiology, University of Nottingham, Nottingham, UK
European region than in any other region of the world. ${ }^{1-4}$ Smoking kills predominantly by causing lung cancer, chronic obstructive pulmonary disease and myocardial infarction, but also by causing or contributing to the development of a wide range of communicable and other non-communicable disorders ${ }^{5,6}$ This burden of disease, which in the UK alone accounts for nearly half a million hospital admissions, $16 \%$ of all deaths each year and a substantial societal economic burden, can be prevented by helping smokers to quit. ${ }^{7-11}$ However, since quitting smoking also generates substantial improvements in disease progression for many of the conditions caused by smoking, treating smoking dependence should be a key component of the management of all diseases caused by smoking.

Clinical management guidelines for diseases caused by smoking should therefore include, or refer to, guidance on smoking cessation. In 2014, we conducted a review of clinical disease guidelines for a sample of diseases more common among smokers, published between 2000 and 2013, to determine the extent to which smoking cessation was addressed. ${ }^{12}$ Our review found that only $60 \%$ of guidelines reported smoking as a risk factor for the development of the selected diseases, $40 \%$ recommended smoking cessation in disease management and $19 \%$ provided detailed information on smoking cessation support. We have now updated this investigation by exploring the extent to which smoking cessation measures have been incorporated into UK or European clinical management guidelines for a range of diseases recently demonstrated to be at least twice as common among smokers and published since January $2014 .{ }^{5}$

\section{Methods}

We used the same methods as in our previous review to identify guidelines and recommendations published between January 2014 to 2019 relating to any of the 16 diseases established in an extensive review by the Royal College of Physicians to be at least twice as common among smokers, and produced or endorsed by a relevant UK national or European transnational medical specialty association, international professional society or government agency. ${ }^{5,12}$ Of the diseases that met the criterion of being at least twice as common among smokers, seven diseases (cancers of the pharynx and oral cavity, larynx and lung; ischaemic heart disease (IHD); abdominal aortic aneurysm (AAA); chronic obstructive pulmonary disease (COPD) and pneumonia) were included in our previous study (other diseases previously included did not meet 
the criterion for being twice as common among smokers) and an additional nine were bulimia, hearing loss, hernia, laboratoryconfirmed influenza (LCI), peripheral artery disease (PAD), psychosis, rheumatoid arthritis (RA), schizophrenia and sleep apnoea. $^{12}$ We performed comprehensive searches of five electronic databases (Medline, EMBASE, National Institute for Health and Care Excellence (NICE) evidence, Guideline International Network (GIN), and Turning Research Into Practice (TRIP)) to October 2019. We also hand-searched all relevant UK and EU authorised organisation websites, such as the websites of European associations or societies for cardiothoracic surgery (EACTS), cardiology (ESC), hernia (EHS), rheumatism (EULAR), medical oncology (ESMO), respiratory (ERS), and clinical microbiology and infectious diseases. We excluded guidelines produced by and for individual European countries outside the UK (non-UK EU country specific guidelines), quality indicator and social care guidance documents. For updated guidelines, only those published from 2014 were considered. The search strategy for Medline is presented in supplementary material S1.

Titles, abstracts and full texts were screened to select eligible guidelines and data extracted using previously piloted checklist forms. Disagreements were resolved by discussion among the authors. The three outcomes of interest were inclusion in the guidance of identification of smoking as a risk factor or major cause of disease; recommending smoking cessation intervention; and provision of, or reference to, smoking cessation guidelines or recommendations of evidence-based treatments for smoking cessation. Simple descriptive summary statistics were used to report the findings.

\section{Results}

Our searches identified 114,038 hits representing 75,222 separate titles, 389 of which were assessed for eligibility from full text; while those excluded were mostly research studies or non-EU publications (supplementary material S2). Of these, 230 were excluded because they did not report on the conditions of interest (199 papers), were English versions of guidelines produced by non-UK EU countries (22 papers) or were guidelines published for the first time before 2014 (nine papers). Thus, there were 159 disease management guidelines eligible for inclusion in the review. For some of the conditions of interest, guidelines were found where multiple conditions were included together in the same guidelines (pharynx/oral cavity and larynx cancers; ischaemic heart disease and peripheral artery disease; and psychosis and schizophrenia), in such cases these conditions were reported together. A full list of eligible guidelines is provided in supplementary material S3.

Just under half (78; 49\%) of the 159 included guidelines, comprising 37 UK and 41 European specialty association, international professional society or government agency publications mentioned smoking. ${ }^{13-90}$ Of the 81 that made no reference to smoking, $48 \%$ were from the UK (Table 1). ${ }^{90-170}$ Smoking was mentioned as a risk factor for the development of the disease by 69 (43\%) guidelines, a statement recommending smoking cessation was included in 50 (31\%) and reference to specific treatments for smoking cessation or to a smoking cessation guideline in 30 (19\%). The numbers of guidelines including smoking guidance, and the nature of the guidance included, are summarised in relation to the study disease groups in Table 1.

\section{Comparison with previous review findings}

Although different smoking related diseases were considered, the proportions of guidelines reporting smoking as a risk factor, offering cessation advice or referring to specific cessation guidance in this present review of guidelines published from 2014 to 2019 are very similar to those published between 2000 and 2013 in our previous report $\left(50 \%, 40 \%\right.$ and $19 \%$, respectively). ${ }^{12}$ Direct comparisons for guidelines on diseases included in both our earlier and current review are presented in Table 2.

\section{Discussion}

This study demonstrates that acknowledgement of the role of smoking in disease aetiology and management remains widely ignored in clinical guidelines for diseases strongly related to smoking.

Since the clinical management of smoking-related diseases should include ascertainment of smoking status and delivery of effective smoking cessation support, this represents a significant and sustained neglect of a major reversible cause of disease.

Quitting smoking reduces the progression of COPD, the incidence of acute lung infections and asthma exacerbations, improves lung cancer survival, and reduces the risk of recurrence of myocardial infarction and stroke. ${ }^{171-178}$ Smoking cessation also improves the outcome of head and neck cancer, peripheral artery disease, rheumatoid arthritis, and a range of other conditions. ${ }^{5,179-186}$ Encouraging patients with diseases caused by smoking should therefore be a routine component of disease management, and systematic intervention to treat smoking is a fundamental component of evidence-based smoking cessation guidance. ${ }^{187,188}$ For nearly half of the guidelines on managing diseases caused by smoking included in this study to fail to even mention smoking cessation is clearly a neglect of the overriding duty of care in medical practice.

Although the identified guidelines for smoking cessation are available, there are people who find it difficult to quit in onestep, and a group who are unwilling. Recommendations for those who would like to quit, but cannot overcome the barriers or are unable to do so using a single intervention, is to provide a combination of options. For instance, pharmacological treatment and electronic interventions in combination with psychosocial interventions, intensive counselling, and interactive and tailored advice and support. ${ }^{61,189-192}$ Several Cochrane reviews have supported the effectiveness of these options and have showed enhanced behavioural support focusing on adherence to smoking cessation medications can improve adherence, and therefore recommends that interventions to increase adherence should address the practicalities and perception changes about taking medication. ${ }^{191-195}$ As such, counselling interventions given outside routine clinical care by smoking cessation counsellors, including health educators and psychologists, could assist smokers to quit. ${ }^{195}$

In respect to unwillingness to quit, in the UK about $40 \%$ of smokers do not want to quit, and despite the reduction in smoking rates across Europe since 2000, these rates are less pronounced compared to Australia and North America. ${ }^{1,196,197}$ Reasons for this are influenced by the poor smoke-free legislation and enforcement. ${ }^{196,197}$ Intention and willingness to quit smoking is associated with a variety of different characteristics, especially socio-demographic factors, and includes a combination of low awareness of smoking-associated health risks and lack of previous 
Table 1. Summary of clinical guidelines and recommendations with the reference to smoking

Disease

\section{Number of included guidelines}

Number
mentioning
smoking, $n$ (\%)

Type of reference to smoking, $\mathrm{n}(\%)$
Number not mentioning smoking, $\mathrm{n}(\%)$

\section{Cancer}

Pharynx/oral cavity 10 cancer and larynx cancer

10

Lung cancer

(8 UK, 2 EU)

17

(4 UK, $13 \mathrm{EU})$

Cardiovascular

Abdominal aortic

aneurysm

Ischaemic heart disease

and peripheral artery

disease

11
(4 UK, 6 EU,
1 Intl)

28

(10 UK, 18 EU)

\section{Mental health}

Psychosis and

schizophrenia

\section{Respiratory}

COPD

Pneumonia

Lab confirmed influenza

Sleep apnoea

\section{Others}

Bulimia

Hearing loss

Hernia

Rheumatoid arthritis

Total
18

(11 UK, 5 EU, 2 Intl)

16

(5 UK, $11 \mathrm{EU}$ )

7

(5 UK, 2 EU)

4

(4 UK)

5

(1 UK, 1 EU,

3 Intl)

(5 UK)

8

(3 UK, 2 EU,
3 Intl)

13

(5 UK, 5 EU,
3 Intl)

17

(10 UK, 7 EU)

159

(75 UK, 72 EU, 12 Intl)
$6(60)$

(5 UK, 1 EU)

6 (60)

8 (47)

(2 UK, 6 EU)

(5 UK, 1 EU)

6 (35)

(2 UK, 4 EU)

7 (64)

(3 UK, 4 EU)

7 (64)

(3 UK, 4 EU)

$20(71)$

(8 UK, 12 EU)

17 (61)

(7 UK, 10 EU)

9 (50)

(7 UK, 2 EU)

6 (33)

(4 UK, 2 EU)

9 (50)

3 (30)

(2 UK)

$4(40)$

$6(35) \quad 4(24)$

(2 UK, 4 EU)

(2 UK, $2 \mathrm{EU})$

$5(45)$

2 (18)

(1 UK, 4 EU) (2 EU)

$15(54)$

7 (25)

(5 UK, 10

(3 UK, 4 EU)

$\mathrm{EU})$

8 (44)

(6 UK, $2 \mathrm{EU})$

$9(50)$

(4 UK, $3 \mathrm{EU}$, 2 Intl)

$13(81)$

$13(81)$

(5 UK, 8 EU)

6 (36)

5 (31)

3 (19)

(5 UK, 8 EU)

1 (14)

(1 UK)

$0(0)$

1 (20)

1 (20)

(1 Intl)

(1 Intl)

(1 UK)

1 (14)

(1 UK)

$0(0)$

(1 UK)

(4 UK, 2 EU)

$4(100)$

(4 UK)

$0(0)$

$0(0)$

4 (80)

(1 UK, 1 EU,

2 Intl)

$0(0)$

1 (12)

(1 Intl)

$0(0)$

$0(0)$

$0(0)$

$5(100)$

(5 UK)

1 (12)

(1 Intl)

$0(0)$

$0(0)$

7 (88)

(3 UK, $1 \mathrm{EU}$, 3 Intl)

7 (54)

(3 UK, $2 \mathrm{EU}$,

7 (54)

$1(8)$

2 (15)

6 (46)

(3 UK, 2 EU, (1 UK)

(2 Intl)

(2 UK, 3 EU, 1 Intl)

5 (29)

$4(24)$

4 (24)

$0(0)$

12 (71)

(3 UK, 1 EU)

(2 UK, 2 EU)

69 (43\%)

50 (31\%)

$30(19 \%)$

(7 UK, 5 EU)

\section{8 (49\%)}

(33 UK, 33

3 Intl)

(17 UK,

81 (51\%) 3 Intl)
(38 UK, $34 \mathrm{EU}$, 9 Intl)

$\mathrm{COPD}=$ chronic obstructive pulmonary disease; $\mathrm{EU}=$ European; $\mathrm{Intl}=$ international. 
Table 2. Comparison of clinical guidelines reporting on smoking as a risk factor and smoking recommendations of conditions assessed in both the previous and current review

\begin{tabular}{|c|c|c|c|c|c|c|}
\hline \multirow[t]{2}{*}{$\begin{array}{l}\text { Conditions reported in both } \\
\text { reviews }\end{array}$} & \multicolumn{2}{|c|}{ Number of guidelines } & \multicolumn{2}{|c|}{$\begin{array}{l}\text { Number providing smoking } \\
\text { cessation advice }\end{array}$} & \multicolumn{2}{|c|}{$\begin{array}{l}\text { Number providing specific } \\
\text { cessation treatment / } \\
\text { guideline reference }\end{array}$} \\
\hline & $2000-13$ & 2014-19 & $2000-13$ & 2014-19 & 2000-13 & 2014-19 \\
\hline Pharynx/oral cancer & 2 & 10 & 2 & 3 & 2 & 2 \\
\hline Lung cancer & 26 & 17 & 14 & 6 & 4 & 4 \\
\hline Cardiovascular disease & 21 & 29 & 16 & 20 & 13 & 9 \\
\hline Respiratory disease & 11 & 32 & 9 & 7 & 6 & 6 \\
\hline
\end{tabular}

quit attempts. ${ }^{1,198}$ Hence, for those unwilling to quit, evidence has shown provision of incentives improve smoking cessation rates and the effectiveness that could be sustained even after the withdrawal of incentives. ${ }^{198,199}$ In addition, use of comprehensive tobacco control programmes, which include mass media campaigns, can be effective in changing smoking behaviour; and this may be combined with other components of a comprehensive tobacco control policy. ${ }^{200}$ This approach would help address environments where there are other non-personal influences on smoking. ${ }^{200,201}$ Hence, health impact and promotion information, and improving awareness about quit options and combinations might increase willingness to use smoking cessation.

Our study has one main limitation related to the use of only documents published in the English language. However, we used robust search strategies and screening methods to identify and assess the eligibility of the clinical guidelines included in the review. It is therefore unlikely that any guidelines we did not identify would have a significant impact on our findings. Since the indexing of clinical guidelines is still being developed, we ensured that our search strategies were sensitive and hence identified many publications that were not relevant. Some of the included guidelines were in the form of a very short consensus document or a shortened updated guideline; therefore, due to the restrictions on the length of the documents it is likely that smoking or smoking cessation practice could not be included, but in many cases these documents made no reference to smoking.

The consequence of the omission of smoking cessation management from clinical guidance is likely to be that smoking is not addressed by practitioners delivering care for people with these conditions. We conclude that the role of smoking as a cause of disease, and of smoking cessation in disease management, remains substantially overlooked and neglected in clinical practice, even in relation to the diseases most strongly related to smoking.

\section{Supplementary material}

Additional supplementary material may be found in the online version of this article at www.rcpjournals.org/clinmedicine: S1 - Search strategy for Medline for cancer diseases.

S2 - PRISMA flow chart of search.

S3 - List of eligible guidelines.

\section{Funding}

The work was funded by Cancer Research UK.

\section{References}

1 Office for National Statistics. Adult smoking habits in the UK: 2018. London: ONS, 2019. www.ons.gov.uk/peoplepopulation andcommunity/healthandsocialcare/healthandlifeexpectancies/ bulletins/adultsmokinghabitsingreatbritain/2018 [Accessed 30 April 2020].

2 World Health Organization. WHO Global report on trends in prevalence of tobacco smoking 2000-2025. WHO, 2018.

3 World Health Organization. WHO Report on the global tobacco epidemic. WHO, 2019. www.who.int/tobacco/global_report/en [Accessed 19 February 2020].

4 World Health Organization. Tobacco: Data and statistics. WHO. www.euro.who.int/en/health-topics/disease-prevention/tobacco/ data-and-statistics [Accessed 30 April 2020].

5 Royal College of Physicians. Hiding in plain sight: Treating tobacco dependency in the NHS. London: RCP, 2018.

6 National Center for Chronic Disease Prevention and Health Promotion (US) Office on Smoking and Health. The health consequences of smoking - 50 years of progress. a report of the surgeon general. Atlanta: Centers for Disease Control and Prevention, 2014.

7 NHS Digital. Statistics on smoking, England - 2019. NHS, 2019. https://digital.nhs.uk/data-and-information/publications/statistical/ statistics-on-smoking/statistics-on-smoking-england-2019 [Accessed 19 February 2020]

8 Aune D, Schlesinger S, Norat T, Riboli E. Tobacco smoking and the risk of abdominal aortic aneurysm: a systematic review and meta-analysis of prospective studies. Sci Rep 2018;8:14786.

9 Baskaran V, Murray RL, Hunter A, Lim WS, McKeever TM. Effect of tobacco smoking on the risk of developing community acquired pneumonia: A systematic review and meta-analysis. PLoS One 2019;14:e0220204.

10 Joseph RM, Movahedi M, Dixon WG, Symmons DPM. Smokingrelated mortality in patients with early rheumatoid arthritis: a retrospective cohort study using the clinical practice research datalink. Arthritis Care and Research 2016;68:1598-606.

11 Braeken DCW, Rohde GGU, Franssen FME et al. Risk of community-acquired pneumonia in chronic obstructive pulmonary disease stratified by smoking status: A population-based cohort study in the United Kingdom. Int J COPD 2017;12:2425-32.

12 Bogdanovica I, Agrawal AS, Gregory BB, Britton C], Leonardi-Bee J. What is the quality of smoking cessation advice in guidelines of tobacco-related diseases? Clin Med 2015;15:546-9.

13 Public Health England. Abdominal Aortic Aneurysm Screening Programme Nurse Specialist Best Practice Guidelines. London: PHE, 2016.

14 Public Health England. NHS Abdominal Aortic Aneurysm (AAA) Screening Programme: Essential elements in providing an $A A A$ screening and surveillance programme. London: PHE, 2017. 
15 Earnshaw ]J, Lees T. Update on screening for abdominal aortic aneurysm. Eur J Vascular and Endovascular Surgery 2017:54:1-2.

16 Hill AT, Sullivan AL, Chalmers JD et al. British thoracic society guideline for bronchiectasis in adults. Thorax 2019;74(Suppl 1):1-69.

17 National Institute for Health and Care Excellence. Chronic obstructive pulmonary disease (acute exacerbation): antimicrobial prescribing: NICE guideline [NG114]. London: NICE. 2018.

18 National Institute for Health and Care Excellence. Chronic obstructive pulmonary disease in over 16s: diagnosis and management: NICE guideline [NG115]. London: NICE, 2018.

19 North J, Osborne W. ASCN UK Guideline: Parastomal hernias. British Journal of Nursing. 2017;26:S6-13.

20 Scottish Intercollegiate Guidelines Network. SIGN 148: Acute coronary syndrome. Edinburgh: SIGN, 2016.

21 Scottish Intercollegiate Guidelines Network. SIGN 152: Cardiac arrhythmias in coronary heart disease. Edinburgh: SIGN, 2018.

22 National Institute for Health and Care Excellence. Cardiovascular disease: risk assessment and reduction, including lipid modification: Clinical guideline [CG181]. London: NICE, 2018.

23 Scottish Intercollegiate Guidelines Network. SIGN 147: Management of chronic heart failure. Edinburgh: SIGN, 2016.

24 Scottish Intercollegiate Guidelines Network. SIGN 151: Management of stable angina. Edinburgh: SIGN, 2018.

25 National Institute for Health and Care Excellence. Peripheral arterial disease: diagnosis and management: Clinical guideline [CG147]. London: NICE, 2018.

26 Scottish Intercollegiate Guidelines Network. SIGN 149: Risk estimation and the prevention of cardiovascular disease. Edinburgh: SIGN, 2017.

27 National Institute for Health and Care Excellence. Stroke and transient ischaemic attack in over 16s: diagnosis and management: NICE guideline [NG128]. London: NICE, 2019.

28 National Institute for Health and Care Excellence. Psychosis and schizophrenia in adults: prevention and management: Clinical guideline [CG178]. London: NICE, 2019.

29 National Collaborating Centre for Chronic Conditions (UK). Rheumatoid arthritis: National clinical guideline for management and treatment in adults: NICE Clinical Guidelines, No. 79 London; Royal College of Physicians, 2018.

30 Scottish Intercollegiate Guidelines Network. SIGN 142: Management of osteoporosis and the prevention of fragility fractures. Edinburgh: SIGN, 2015.

31 Paleri V, Roland N. Introduction to the United Kingdom National Multidisciplinary Guidelines for Head and Neck Cancer. J Laryngol Otol 2016;130(Suppl 2):S3-4.

32 Mehanna H, Kong A, Ahmed S. Recurrent head and neck cancer: United Kingdom National Multidisciplinary Guidelines. J Laryngol Otol 2016;130:S181-90.

33 Kerawala C, Roques T, Jeannon JP, Bisase B. Oral cavity and lip cancer: United Kingdom National Multidisciplinary Guidelines. J Laryngol Otol 2016;130:S83-9.

34 Mcallister-Williams RH, Baldwin DS, Cantwell R et al. British Association for Psychopharmacology consensus guidance on the use of psychotropic medication preconception, in pregnancy and postpartum 2017. J Psychopharmacol 2017;31:519-52.

35 National Institute for Health and Care Excellence. Lung cancer: Diagnosis and management: NICE guideline [NG122]. London: NICE, 2008.

36 Scottish Intercollegiate Guidelines Network. SIGN 137: Management of lung cancer. Edinburgh: SIGN, 2014.

37 National Institute for Health and Clinical Excellence. Cancer of the upper aerodigestive tract: Assessment and management in people aged 16 and over: NICE guideline [NG36]. London: NICE, 2019.

38 National Institute for Health and Clinical Excellence. Suspected cancer: recognition and referral: NICE guideline [NG12]. London: NICE, 2015.
39 British Thoracic Society. British Thoracic Society guidelines for the management of community acquired pneumonia in adults: Update 2009. BTS, 2015.

40 National Institute for Health and Care Excellence. Coexisting existing severe mental illness and substance misuse: Community health and social care services: NICE guideline [NG58]. London: NICE, 2019.

41 Royal College of Psychiatrists. Consensus statement on high-dose antipsychotic medication. RCPsych, 2014.

42 Cooper SJ, Reynolds GP, Barnes TRE et al. BAP guidelines on the management of weight gain, metabolic disturbances and cardiovascular risk associated with psychosis and antipsychotic drug treatment. J Psychopharmacol 2016;30:717-48.

43 Kuipers E, Yesufu-Udechuku A, Taylor C et al. Management of psychosis and schizophrenia in adults: summary of updated NICE guidance. BMJ 2014;348:g1173.

44 North West NHS Podiatry Services Clinical Effectiveness Group Rheumatology. Guidelines for the management of foot health for people with rheumatoid arthritis. North West NHS Podiatry Services Clinical Effectiveness Group, 2014.

45 Javed A, Arthur H, Curtis L, Hansen L, Pappa S. Practical guidance on the use of lurasidone for the treatment of adults with schizophrenia. Neurol Ther 2019;8:215-30.

46 ACPGBI Parastomal Hernia Group. Prevention and treatment of parastomal hernia: a position statement on behalf of the Association of Coloproctology of Great Britain and Ireland. Colorectal Dis 2018;20(Suppl 2):5-19.

47 British Hernia Society, Royal College of Surgeons of England. Commissioning guide: Groin Hernia Commissioning guide. BHS, 2016.

48 O'Driscoll BR, Howard LS, Earis ] et al. BTS guideline for oxygen use in adults in healthcare and emergency settings. Thorax 2017;72(Suppl 1):ii1-90.

49 Hardinge M, Annandale J, Bourne S et al. British Thoracic Society guidelines for Home Oxygen use in adults. Thorax. 2015;70: i1-43.

50 Erbel R, Aboyans V, Boileau C et al. 2014 ESC guidelines on the diagnosis and treatment of aortic diseases. Eur Heart Journal 2014;35:2873-926

51 Cosentino F, Grant PJ, Aboyans V et al. 2019 ESC Guidelines on diabetes, pre-diabetes, and cardiovascular diseases developed in collaboration with the EASD. Eur Heart Journal 2020:41:255323.

52 Wanhainen A, Verzini F, Van Herzeele I et al. Editor's Choice European Society for Vascular Surgery (ESVS) 2019 Clinical Practice Guidelines on the Management of Abdominal Aorto-iliac Artery Aneurysms. European Journal of Vascular and Endovascular Surgery 2019;57:8-93.

53 Riambau V, Böckler D, Brunkwall J et al. Editor's Choice Management of Descending Thoracic Aorta Diseases: Clinical Practice Guidelines of the European Society for Vascular Surgery (ESVS). European Journal of Vascular and Endovascular Surgery 2017:53:4-52

54 Rochester CL, Vogiatzis I, Holland AE et al. An official American Thoracic Society/European Respiratory Society policy statement: Enhancing implementation, use, and delivery of pulmonary rehabilitation. American Journal of Respiratory and Critical Care Medicine 2015;192:1373-86.

55 Maltais F, Decramer M, Casaburi R et al. An official American thoracic society/european respiratory society statement: Update on limb muscle dysfunction in chronic obstructive pulmonary disease. American Journal of Respiratory and Critical Care Medicine 2014:189:15-62.

56 Watz H, Pitta F, Rochester CL et al. An official European respiratory society statement on physical activity in COPD. Eur Resp Journal 2014:44:1521-37. 
57 Canepa M, Straburzynska-Migaj E, Drozdz ] et al. Characteristics, treatments and 1-year prognosis of hospitalized and ambulatory heart failure patients with chronic obstructive pulmonary disease in the European Society of Cardiology Heart Failure Long-Term Registry. Eur J Heart Failure 2018;20:100-10.

58 Grünig E, Eichstaedt C, Barberà J-A et al. ERS statement on exercise training and rehabilitation in patients with severe chronic pulmonary hypertension. Eur Resp Journal 2019;53: 1800332

59 Global Initiative for Chronic Obstructive Lung Disease. Global strategy for the diagnosis, management, and prevention of chronic obstructive pulmonary disease (2020 report). GOLD, 2020.

60 Wedzicha JA, Calverley PMA, Albert RK et al. Prevention of COPD exacerbations: A European Respiratory Society/ American Thoracic Society guideline. Eur Resp Journal 2017;50:1602265.

61 Jiménez-Ruiz CA, Andreas S, Lewis KE et al. Statement on smoking cessation in COPD and other pulmonary diseases and in smokers with comorbidities who find it difficult to quit. Eur Resp Journal 2015;46:61-79.

62 World Health Organization. Environmental noise guidelines for the European region. WHO, 2019.

63 De Simone B, Birindelli A, Ansaloni L et al. Emergency repair of complicated abdominal wall hernias: WSES guidelines. Hernia 2020:24:359-68.

64 Simons MP, Smietanski M, Bonjer HJ et al. International guidelines for groin hernia management. Hernia 2018;22:1-165.

65 Bittner R, Bain K, Bansal VK et al. Update of Guidelines for laparoscopic treatment of ventral and incisional abdominal wall hernias (International Endohernia Society (IEHS)): Part A. Surgical Endoscopy 2019;33:3069-139.

66 Bittner R, Bain K, Bansal VK et al. Update of Guidelines for laparoscopic treatment of ventral and incisional abdominal wall hernias (International Endohernia Society (IEHS)): Part B. Surgical Endoscopy 2019:33:3511-49.

67 Kristensen SD, Knuuti J, Saraste A et al. 2014 ESC/ESA Guidelines on non-cardiac surgery: Cardiovascular assessment and management. Eur Heart Journal 2014;35:2383-431.

68 Zamorano JL, Lancellotti P, Rodriguez Muñoz D et al. 2016 ESC Position Paper on cancer treatments and cardiovascular toxicity developed under the auspices of the ESC Committee for Practice Guidelines. Eur Heart Journal 2016;37:2768-801.

69 Piepoli MF, Hoes AW, Agewall S et al. 2016 European Guidelines on cardiovascular disease prevention in clinical practice. Eur Heart Journal 2016;37:2315-81.

70 Ibanez B, James S, Agewall S et al. 2017 ESC Guidelines for the management of acute myocardial infarction in patients presenting with ST-segment elevation. Eur Heart Journal 2018; 39:119-77.

71 Regitz-Zagrosek V, Roos-Hesselink JW, Bauersachs ] et al. 2018 ESC Guidelines for the management of cardiovascular diseases during pregnancy. Eur Heart Journal 2018;39:3165-241.

72 Knuuti J, Wijns W, Saraste A, Capodanno D et al. 2019 ESC Guidelines for the diagnosis and management of chronic coronary syndromes. Eur Heart Journal 2020;41:407-77.

73 Czerny M, Schmidli J, Adler S, et al. Editor's Choice - Current options and recommendations for the treatment of thoracic aortic pathologies involving the aortic arch: an expert consensus document of the European Association for Cardio-Thoracic Surgery (EACTS) \& the European Society for Vascular Surgery (ESVS). Eur J Vascular and Endovascular Surgery 2019;57:165-98.

74 Adlam D, Alfonso F, Maas A, Vrints C. European Society of Cardiology, acute cardiovascular care association, SCAD study group: a position paper on spontaneous coronary artery dissection. Eur Heart ] 2018;39:3353-68.

75 Simo R, Bradley P, Chevalier D et al. European Laryngological Society: ELS recommendations for the follow-up of patients treated for laryngeal cancer. European Archives of Oto-RhinoLaryngology 2014;271:2469-79.

76 Eberhardt WEE, De Ruysscher D, Weder W et al. 2nd ESMO Consensus Conference in Lung Cancer: Locally advanced stage III non-small-cell lung cancer. Annals of Oncology 2015;26:1573-88.

77 Vansteenkiste ], Crinò L, Dooms C et al. 2nd ESMO consensus conference on lung cancer: Early-stage non-small-cell lung cancer consensus on diagnosis, treatment and follow-up. Annals of Oncology 2014;25:1462-74.

78 Besse B, Adjei A, Baas P et al. 2nd ESMO Consensus Conference on Lung Cancer: Non-small-cell lung cancer first-line/second and further lines in advanced disease. Annals of Oncology 2014; $25: 1475-84$

79 Kauczor HU, Bonomo L, Gaga M et al. ESR/ERS white paper on lung cancer screening. European Radiology 2015;25:2519-31.

80 Planchard D, Popat S, Kerr K et al. Metastatic non-small cell lung cancer: ESMO Clinical Practice Guidelines for diagnosis, treatment and follow-up. Annals of Oncology 2018;29(Suppl 4):iv192-237.

81 Aboyans V, Ricco JB, Bartelink MLEL et al. 2017 ESC guidelines on the diagnosis and treatment of peripheral arterial diseases, in collaboration with the European Society for Vascular Surgery (ESVS). Eur Heart Journal 2018;39:763-816.

82 Williams B, Mancia G, Spiering W et al. 2018 practice guidelines for the management of arterial hypertension of the European society of cardiology and the European society of hypertension ESC/ESH task force for the management of arterial hypertension. Journal of Hypertension 2018;36:2284-309.

83 Venermo M, Sprynger M, Desormais I et al. Follow-up of patients after revascularisation for peripheral arterial diseases: a consensus document from the European Society of Cardiology Working Group on Aorta and Peripheral Vascular Diseases and the European Society for Vascular Surgery. European Journal of Preventive Cardiology 2019;26:1971-84.

84 Hinchliffe RJ, Brownrigg JRW, Apelqvist ] et al. IWGDF guidance on the diagnosis, prognosis and management of peripheral artery disease in patients with foot ulcers in diabetes. Diabetes Metab Res Rev 2016;32(Suppl 1):37-44.

85 Rüther T, Bobes J, De Hert M et al. EPA Guidance on tobacco dependence and strategies for smoking cessation in people with mental illness. European Psychiatry 2014;29:65-82.

86 Hasan A, Falkai P, Wobrock T et al. World Federation of Societies of Biological Psychiatry (WFSBP) Guidelines for Biological Treatment of Schizophrenia Part 3: Update 2015 Management of special circumstances: Depression, Suicidality, substance use disorders and pregnancy and lactation. World Journal of Biological Psychiatry 2015;16:142-70.

87 Combe B, Landewe R, Daien CI et al. 2016 update of the EULAR recommendations for the management of early arthritis. Annals of the Rheumatic Diseases 2017;76:948-59.

88 Agca R, Heslinga SC, Rollefstad S et al. EULAR recommendations for cardiovascular disease risk management in patients with rheumatoid arthritis and other forms of inflammatory joint disorders: 2015/2016 update. Ann Rheum Dis 2017;76:17-28.

89 Ouayoun MC, Chabolle F, De Vito A et al. International consensus (ICON) on the ENT role in diagnosis of obstructive sleep apnea syndrome. Eur Ann Otorhinolaryngol Head Neck Dis 2018;135(1S):S3-6.

90 Rich AL, Baldwin DR, Beckett P et al. ERS statement on harmonised standards for lung cancer registration and lung cancer services in Europe. Eur Resp Journal 2018;52:1800610.

91 Denton CP, Hughes M, Gak N et al. BSR and BHPR guideline for the treatment of systemic sclerosis. Rheumatology 2016;55: 1906-10.

92 Hatemi G, Christensen R, Bang D et al. 2018 Update of the EULAR recommendations for the management of Behcet's syndrome. Annals of the Rheumatic Diseases 2018;77:808-18. 
93 Paraskevas KI, Eckstein HH, Schermerhorn ML. Guideline recommendations for the management of abdominal aortic aneurysms. Angiology 2019;70:688-9.

94 Public Health England. NHS Abdominal Aortic Aneurysm Screening Programme: Clinical guidance and scope of practice for professionals involved in the provision of the ultrasound scan within AAA screening. PHE, 2016.

95 Dalman RL. The 2019 update of the European abdominal aortic aneurysm guidelines. J Vasc Surg 2019;69:633-4.

96 NHS England, National Institute for Health and Care Excellence, National Collaborating Centre for Mental Health. Adult eating disorders: community, inpatient and intensive day patient care. NHS, 2019.

97 NHS England, National Institute for Health and Care Excellence, National Collaborating Centre for Mental Health. Appendices and helpful resources for adult eating disorders: community, inpatient and intensive day patient care. NHS, 2019.

98 National Institute for Health and Care Excellence. Eating disorders: recognition and treatment: NICE quideline [NG69]. London: NICE, 2017.

99 Royal College of Pathologists, Royal College of Physicians, Royal College of Psychiatrists. MARSIPAN: Management of really sick patients with anorexia nervosa. RCPsych, 2018.

100 Robinson P, Rhys Jones W. MARSIPAN: management of really sick patients with anorexia nervosa. BJPsych Advances 2018;24:20-32.

101 Ergan B, Oczkowski S, Rochwerg B et al. European Respiratory Society guidelinea on long-term home non-invasive ventilation for management of COPD. Eur Respir J 2019;54:1901003.

102 Vogiatzis I, Rochester CL, Spruit MA et al. Increasing implementation and delivery of pulmonary rehabilitation: key messages from the new ATS/ERS policy statement. Eur Respir ] 2016:47:1336-41.

103 Wedzicha JAEC-C, Miravitlles M, Hurst JR et al. Management of COPD exacerbations: a European Respiratory Society/American Thoracic Society guideline. Eur Respir J 2017;49:1600791.

104 Lopez-Escamez JA, Carey ], Chung WH et al. Diagnostic criteria for Meniere's disease. J Vestib Res 2015:25:1-7.

105 Magnan J, Ozgirgin ON, Trabalzini F et al. European position statement on diagnosis, and treatment of Meniere's disease. J Int Adv Otol 2018;14:317-21.

106 British Academy of Audiology. Guidance for primary care: Direct referral of adults with hearing difficulty to audiology services. BAA, 2016.

107 Ftouh S, Harrop-Griffiths K, Harker M et al. Hearing loss in adults, assessment and management: summary of NICE guidance. BM] 2018;361:k2219.

108 National Institute for Health and Care Excellence. Hearing loss in adults: assessment and management: NICE guideline [NG98]. London: NICE, 2018.

109 Nevoux ], Barbara M, Dornhoffer ] et al. International consensus (ICON) on treatment of Meniere's disease. Eur Ann Otorhinolaryngol Head Neck Dis 2018;135:S29-32.

110 Marx M, Younes E, Chandrasekhar SS et al. International consensus (ICON) on treatment of sudden sensorineural hearing loss. Eur Ann Otorhinolaryngol Head Neck Dis 2018:135:S23-8.

111 Sheen AJ, Stephenson BM, Lloyd DM et al. 'Treatment of the sportsman's groin': British Hernia Society's 2014 position statement based on the Manchester Consensus Conference. $\mathrm{Br}$ ] Sports Med 2014;48:1079-87.

112 Campanelli G. Endorsement of the Herniasurge guidelines by the European Hernia Society. Hernia 2018;22:169.

113 Antoniou SA, Agresta F, Garcia Alamino JM et al. European Hernia Society guidelines on prevention and treatment of parastomal hernias. Hernia 2018;22:183-98.

114 National Institute for Health and Care Excellence. Reinforcement of a permanent stoma with a synthetic or biological mesh to prevent a parastomal hernia: Interventional procedures guidance [IPG654]. NICE, 2019.

115 Bittner R, Montgomery MA, Arregui E et al. Update of guidelines on laparoscopic (TAPP) and endoscopic (TEP) treatment of inguinal hernia (International Endohernia Society). Surg Endosc 2015:29:289-321.

116 Miserez M, Conze ], Peeters E et al. Update with level 1 studies of the European Hernia Society guidelines on the treatment of inguinal hernia in adult patients. Hernia 2014;18 151-63.

117 Galie N, Humbert M, Vachiery JL et al. 2015 ESC/ERS Guidelines for the diagnosis and treatment of pulmonary hypertension. Eur Heart Journal 2016;37:67-119.

118 Sousa-Uva M, Neumann FJ, Ahlsson A, Alfonso F, Banning AP Benedetto $U$ et al. 2018 ESC/EACTS Guidelines on myocardial revascularization. Eur ] Cardio-thoracic Surgery 2019;55:4-90.

119 National Institute for Health and Care Excellence. Atrial fibrillation: management: Clinical guideline [CG180]. NICE, 2014

120 Ntaios G, Dziedzic T, Michel P et al. European Stroke Organisation (ESO) guidelines for the management of temperature in patients with acute ischemic stroke. Int J Stroke 2015;10:941-9.

121 Joseph J, Velasco A, Hage FG, Reyes E. Guidelines in review: Comparison of ESC and ACC/AHA guidelines for the diagnosis and management of patients with stable coronary artery disease. J Nucl Cardiol 2018;25:509-15.

122 Steeds RP, Wheeler R, Bhattacharyya S et al. Stress echocardiography in coronary artery disease: a practical guideline from the British Society of Echocardiography. Echo Res Pract 2019;6:G17-33.

123 Lancellotti P, Pellikka PA, Budts W et al. The clinical use of stress echocardiography in non-ischaemic heart disease: recommendations from the European Association of Cardiovascular Imaging and the American Society of Echocardiography. Eur Heart ] Cardiovasc Imaging 2016;17:1191-229.

124 Public Health England. Guidelines on the management of outbreaks of influenza-like illness in care homes. London: PHE, 2018.

125 Public Health England. PHE guidance on use of antiviral agents for the treatment and prophylaxis of seasonal influenza. London: PHE, 2019.

126 Public Health England. Influenza: the green book, chapter 19 London: PHE, 2019.

127 Public Health England. Management of infection guidance for primary care for consultation and local adaptation October 2014. Report No: 1204186170. London: PHE, 2014.

128 Dignan FL, Clark A, Aitken C et al. BCSH/BSBMT/UK clinical virology network guideline: diagnosis and management of common respiratory viral infections in patients undergoing treatment for haematological malignancies or stem cell transplantation. British Journal of Haematology 2016;173:380-93.

129 Pracy P, Loughran S, Good J, Parmar S, Goranova R. Hypopharyngeal cancer: United Kingdom National Multidisciplinary Guidelines. J Laryngol Otol 2016;130:S104-10.

130 Jones TM, De M, Foran B, Harrington K, Mortimore S. Laryngeal cancer: United Kingdom National Multidisciplinary guidelines. J Laryngol Otol 2016;130:S75-82.

131 Giammarile F, Schilling C, Gnanasegaran G et al. The EANM practical guidelines for sentinel lymph node localisation in oral cavity squamous cell carcinoma. Eur ] Nucl Med Mol Imaging 2019;46:623-37.

132 Howard L, Barden S, Condliffe R et al. British Thoracic Society Guideline for the initial outpatient management of pulmonary embolism (PE). Thorax 2018;73(Suppl 2):ii1-29.

133 Vilmann P, Clementsen PF, Colella S et al. Combined endobronchial and esophageal endosonography for the diagnosis and staging of lung cancer: European Society of Gastrointestinal Endoscopy (ESGE) Guideline, in cooperation with the European Respiratory Society (ERS) and the European Society of Thoracic Surgeons (ESTS). Endoscopy 2015;47:545-59. 
134 Bibby AC, Dorn P, Psallidas I et al. ERS/EACTS statement on the management of malignant pleural effusions. Eur Respir ] 2018;52:1800349.

135 De Ruysscher D, Faivre-Finn C, Moeller D et al. European Organization for Research and Treatment of Cancer (EORTC) recommendations for planning and delivery of high-dose, high precision radiotherapy for lung cancer. Radiother Oncol 2017:124:1-10.

136 Baas P, Fennell D, Kerr KM et al. Malignant pleural mesothelioma: ESMO Clinical Practice Guidelines for diagnosis, treatment and follow-up. Ann Oncol 2015;26(Suppl 5):v31-9.

137 De Leyn P, Dooms C, Kuzdzal ] et al. Revised ESTS guidelines for preoperative mediastinal lymph node staging for non-small-cell lung cancer. Eur ] Cardiothorac Surg 2014;45:787-98.

138 Kerr KM, Bubendorf L, Edelman M] et al. Second ESMO consensus conference on lung cancer: pathology and molecular biomarkers for non-small-cell lung cancer. Ann Oncol 2014;25:1681-90.

139 National Institute for Health and Care Excellence. Venous thromboembolism in over 16s: reducing the risk of hospital-acquired deep vein thrombosis or pulmonary embolism: NICE guideline [NG89]. NICE, 2018.

140 Fischer A, Antoniou KM, Brown KK et al. An official European Respiratory Society/American Thoracic Society research statement: interstitial pneumonia with autoimmune features. Eur Respir ] 2015;46:976-87.

141 Torres A, Niederman MS, Chastre ] et al. International ERS/ESICM ESCMID/ALAT guidelines for the management of hospitalacquired pneumonia and ventilator-associated pneumonia. Eur Respir ] 2017;50: 1700582

142 Public Health England. Pneumococcal: the green book, chapter 25. London: PHE, 2020

143 National Institute for Health and Care Excellence. Pneumonia (community-acquired): antimicrobial prescribing: NICE guideline [NG138]. NICE, 2019.

144 National Institute for Health and Care Excellence. Pneumonia (hospital-acquired): antimicrobial prescribing: NICE guideline [NG139]. NICE, 2019.

145 National Institute for Health and Care Excellence. Pneumonia in adults: diagnosis and management: Clinical guideline [CG191]. NICE, 2014.

146 Pollak TA, Lennox BR, Müller S et al. Autoimmune psychosis: an international consensus on an approach to the diagnosis and management of psychosis of suspected autoimmune origin. Lancet Psychiatry 2020;7:93-108.

147 Gupta S, Cahill JD, Miller R. Deprescribing antipsychotics: a guide for clinicians. BJPsych Advances 2018;24:295-302.

148 Schultze-Lutter F, Michel C, Schmidt S] et al. EPA quidance on the early detection of clinical high risk states of psychoses. Eur Psychiatry 2015;30:405-16.

149 Vollm BA, Clarke M, Herrando VT et al. European Psychiatric Association (EPA) guidance on forensic psychiatry: Evidence based assessment and treatment of mentally disordered offenders. Eur Psychiatry 2018;51:58-73.

150 Gaebel W, Grossimlinghaus I, Kerst A et al. European Psychiatric Association (EPA) quidance on the quality of eMental health interventions in the treatment of psychotic disorders. Eur Arch Psychiatry Clin Neurosci 2016;266:125-37.

151 Patel MX, Sethi FN, Barnes TR et al. Joint BAP NAPICU evidencebased consensus guidelines for the clinical management of acute disturbance: De-escalation and rapid tranquillisation. J Psychopharmacol 2018;32:601-40.

152 National Institute for Health and Care Excellence. Mental health of adults in contact with the criminal justice system: NICE guideline [NG66]. NICE, 2017.

153 National Institute for Health and Care Excellence. Mental health problems in people with learning disabilities: prevention, assessment and management. NICE guideline [NG54]. NICE, 2016.
154 Hasan A, Falkai P, Wobrock T et al. World Federation of Societies of Biological Psychiatry (WFSBP) guidelines for biological treatment of schizophrenia - a short version for primary care. Int J Psychiatry Clin Pract 2017;21:82-90.

155 Dejaco C, Singh YP, Perel P et al. 2015 recommendations for the management of polymyalgia rheumatica: a European League Against Rheumatism/American College of Rheumatology collaborative initiative. Arthritis Rheumatology 2015;67:2569-80.

156 Furer V, Rondaan C, Heijstek MW et al. 2019 update of EULAR recommendations for vaccination in adult patients with autoimmune inflammatory rheumatic diseases. Ann Rheum Dis 2020;79:39-52.

157 Ledingham J, Snowden N, Ide Z. Diagnosis and early management of inflammatory arthritis. BMJ 2017;358:j3248.

158 Smolen JS, Landewe R, Breedveld FC et al. EULAR recommendations for the management of rheumatoid arthritis with synthetic and biological disease-modifying antirheumatic drugs: 2013 update. Ann Rheum Dis 2014;73:492-509.

159 Smolen JS, Landewe R, Bijlsma J et al. EULAR recommendations for the management of rheumatoid arthritis with synthetic and biological disease-modifying antirheumatic drugs: 2016 update. Ann Rheum Dis 2017;76:960-77.

160 Ramos-Casals M, Brito-Zerón P, Bombardieri S et al. EULAR recommendations for the management of Sjögren's syndrome with topical and systemic therapies. Ann Rheum Dis 2020;79:3-18.

161 Rangan A, Falworth M, Watts AC et al. Investigation and Management of Periprosthetic Joint Infection in the Shoulder and Elbow: Evidence and consensus based guidelines of the British Elbow and Shoulder Society. Shoulder Elbow 2018;10(1 Suppl): S5-19.

162 National Institute for Health and Care Excellence. Rheumatoid arthritis in adults: management: NICE guideline [NG100]. NICE, 2018.

163 Holroyd CR, Seth R, Bukhari M et al. The British Society for Rheumatology biologic DMARD safety guidelines in inflammatory arthritis. Rheumatology 2019;58:e3-42.

164 Price EJ, Rauz S, Tappuni AR et al. The British Society for Rheumatology guideline for the management of adults with primary Sjogren's Syndrome. Rheumatology 2017;56:e24-48.

165 Malaviya AP, Ledingham J, Bloxham J et al. The 2013 BSR and BHPR guideline for the use of intravenous tocilizumab in the treatment of adult patients with rheumatoid arthritis. Rheumatology 2014;53:1344-6.

166 Randerath W, Verbraecken J, Andreas S et al. Definition, discrimination, diagnosis and treatment of central breathing disturbances during sleep. Eur Respir J 2017;49:1600959.

167 National Institute for Health and Care Excellence. Hypoglossal nerve stimulation for moderate to severe obstructive sleep apnoea: Interventional procedures guidance [IPG598]. NICE, 2017.

168 de Raaff CAL, Gorter-Stam MAW, de Vries N et al. Perioperative management of obstructive sleep apnea in bariatric surgery: a consensus guideline. Surg Obes Relat Dis 2017;13:1095-109.

169 Netzer NC, Ancoli-Israel S, Bliwise DL et al. Principles of practice parameters for the treatment of sleep disordered breathing in the elderly and frail elderly: the consensus of the International Geriatric Sleep Medicine Task Force. Eur Respir ] 2016;48:992-1018.

170 TASC Steering Committee, Jaff MR, White C] et al. An Update on Methods for Revascularization and Expansion of the TASC Lesion Classification to Include Below-the-Knee Arteries: A Supplement to the Inter-Society Consensus for the Management of Peripheral Arterial Disease (TASC II). Vasc Med 2015;20:465-78.

171 Anthonisen NR, Connett JE, Murray RP. Smoking and lung function of Lung Health Study participants after 11 years. Am J Respir Crit Care Med 2002;166:675-9.

172 Wu J, Sin DD. Improved patient outcome with smoking cessation: When is it too late? Int J Chron Obstruct Pulmon Dis 2011;6 259-67. 
173 Parsons A, Daley A, Begh R, Aveyard P. Influence of smoking cessation after diagnosis of early stage lung cancer on prognosis: Systematic review of observational studies with meta-analysis. BMJ 2010;340:b5569.

174 Woodward M, Lam TH, Barzi F et al. Smoking, quitting, and the risk of cardiovascular disease among women and men in the Asia-Pacific region. Int J Epi 2005;34:1036-45.

175 Naidoo B, Stevens W, McPherson K. Modelling the short-term consequences of smoking cessation in England on the hospitalisation rates for acute myocardial infarction and stroke. Tobacco Control 2000;9:397-400.

176 Honjo $\mathrm{K}$, Iso $\mathrm{H}$, Tsugane $\mathrm{S}$ et al. The effects of smoking and smoking cessation on mortality from cardiovascular disease among Japanese: Pooled analysis of three large-scale cohort studies in Japan. Tobacco Control 2010;19:50-7.

177 He Y, Jiang B, Li LS et al. Changes in smoking behavior and subsequent mortality risk during a 35-year follow-up of a cohort in Xi'an, China. Am J Epidemiol 2014;179:1060-70.

178 Bjartveit K, Tverdal A. Health consequences of sustained smoking cessation. Tobacco Control 2009;18:197-205.

179 Amato KAD, Hyland A, Reed R et al. Tobacco cessation may improve lung cancer patient survival. J Thoracic Oncology 2015;10:1014-9.

180 Barrera R, Shi W, Amar D et al. Smoking and timing of cessation: Impact on pulmonary complications after thoracotomy. Chest 2005;127:1977-83.

181 Lugg ST, Tikka T, Agostini PJ et al. Smoking and timing of cessation on postoperative pulmonary complications after curative-intent lung cancer surgery. J Cardio Surg 2017;12:52.

182 Choi SH, Terrell JE, Bradford CR et al. Does Quitting Smoking Make a Difference Among Newly Diagnosed Head and Neck Cancer Patients? Nicotine \& Tobacco Res 2016:18:2216-24.

183 Jerjes W, Upile T, Radhi H et al. The effect of tobacco and alcohol and their reduction/cessation on mortality in oral cancer patients: Short communication. Head \& Neck Oncology 2012;4:6.

184 Koshiaris C, Aveyard P, Oke ] et al. Smoking cessation and survival in lung, upper aero-digestive tract and bladder cancer: Cohort study: $\mathrm{Br}$ J Cancer 2017;117:1224-32.

185 Armstrong EJ, Wu J, Singh GD et al. Smoking cessation is associated with decreased mortality and improved amputation-free survival among patients with symptomatic peripheral artery disease. J Vas Surg 2014;60:1565-71.

186 Di Giuseppe D, Discacciati A, Orsini N, Wolk A. Cigarette smoking and risk of rheumatoid arthritis: A dose-response meta-analysis. Arthritis Res Ther 2014;16:R61.

187 National Institute for Health and Care Excellence. Smoking: acute, maternity and mental health services: Public health guideline [PH48]. NICE, 2013.

188 National Institute for Health and Care Excellence. Stop smoking interventions and services: NICE quideline [NG92]. NICE, 2018.
189 Chen YF, Madan J, Welton N et al Effectiveness and cost-effectiveness of computer and other electronic aids for smoking cessation: a systematic review and network meta-analysis. NIHR Journals Library, 2012

190 Robinson J, McEwen A, Heah R, Papadakis S. A 'Cut-Down-ToStop' intervention for smokers who find it hard to quit: a qualitative evaluation. BMC Public Health 2019;19:403.

191 Taylor GM], Dalili MN, Semwal M et al. Internet-based interventions for smoking cessation. Cochrane Database Syst Rev 2017;9: CD007078

192 Matkin W, Ordonez-Mena JM, Hartmann-Boyce J. Telephone counselling for smoking cessation. Cochrane Database Syst Rev 2019;5:CD002850.

193 Hollands GJ, Naughton F, Farley A, Lindson N, Aveyard P. Interventions to increase adherence to medications for tobacco dependence. Cochrane Database Syst Rev 2019;8:CD009164.

194 van Eerd EAM, van der Meer RM, van Schayck OCP, Kotz D. Smoking cessation for people with chronic obstructive pulmonary disease. Cochrane Database Syst Rev 2016:8:CD010744.

195 Lancaster T, Stead LF. Individual behavioural counselling for smoking cessation. Cochrane Database Syst Rev 2017;3: CD001292.

196 Neuberger M. Tobacco control: prevention and cessation in Europe. MEMO 2019:12:156-61.

197 Joossens L, Raw M. The tobacco control scale 2016 in Europe: Association of European Cancer Leagues, 2017.

198 Treskova M, Aumann I, Hagemann N, Graf von der Schulenburg $\mathrm{JM}$. Analysis of driving factors of willingness to use and willingness to pay for existing pharmacological smoking cessation aids among young and middle-aged adults in Germany. European Respiratory Journal. 2016;48:PA1534.

199 Notley C, Gentry S, Livingstone-Banks J, Bauld L, Perera R Hartmann-Boyce J. Incentives for smoking cessation. Cochrane Database Syst Rev 2019;7:CD004307.

200 Bala MM, Strzeszynski L, Topor-Madry R. Mass media interventions for smoking cessation in adults. Cochrane Database Syst Rev 2017:11:CD004704

201 Milcarz K, Makowiec-Dabrowska T, Bak-Romaniszyn L, Kaleta D. Smoking patterns and smoking cessation willingness-a study among beneficiaries of government welfare assistance in Poland. Int J Environ Res Public Health 2017;14:131.

Address for correspondence: Dr Winifred Ekezie, Division of Epidemiology and Public Health, University of Nottingham, City Hospital Campus, Hucknall Road, Nottingham NG5 1PB, UK. Email:winifred.ekezie@gmail.com 


\section{Royal College
of Physicians}

\section{Flexible

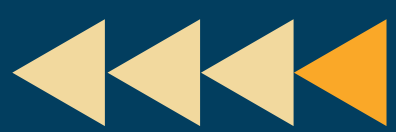 \\ portfolio training}

Flexible portfolio training (FPT) is a new initiative within higher specialty training offered by Health Education England and the Royal College of Physicians. It protects 1 day a week (or $20 \%$ time equivalent) for professional development.

FPT acts as the perfect complement to clinical training, providing protected time away from clinical medicine to pursue other avenues. A flexible portfolio trainee's non-clinical day will be focused on one of four pathways:

$>$ medical education

$\checkmark$ quality improvement

$>$ research

$>$ clinical informatics.
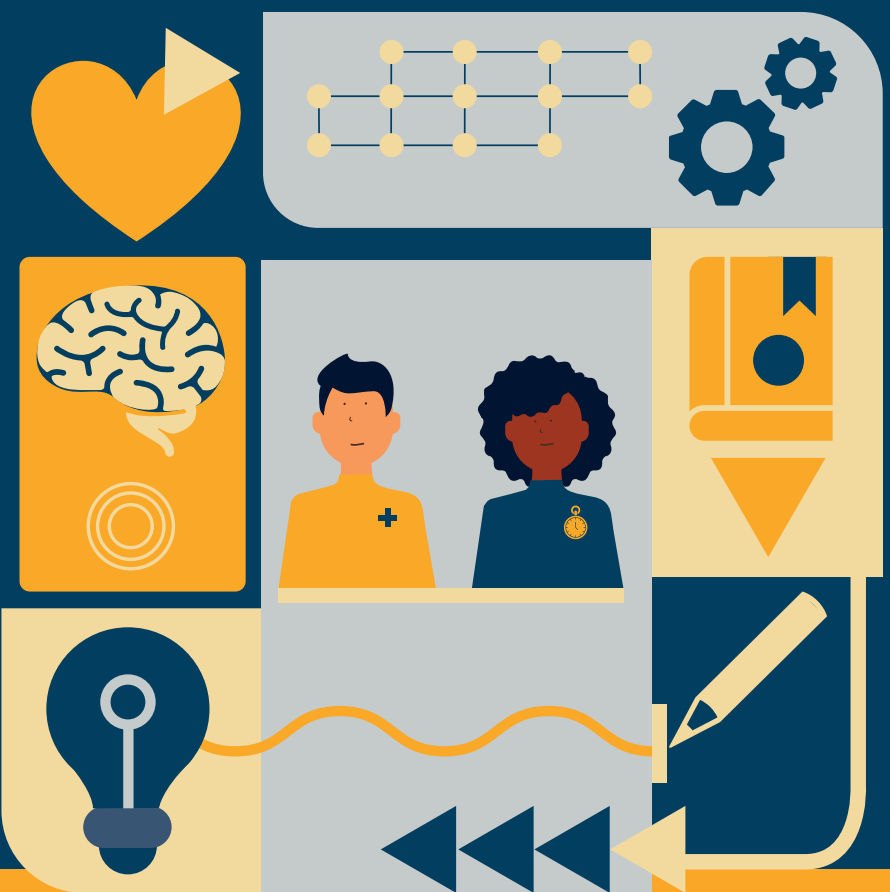

New FPT resources, including a handbook for trainees

and supervisors, are now available from

www.rcplondon.ac.uk/projects/flexible-portfolio-training

Email flexibleportfoliotraining@rcplondon.ac.uk for more information 